\title{
Taste compounds from crude extract of bekkai lan (Albertisia papuana Becc.)
}

\author{
Sulvi Purwayanti ${ }^{1}$, Murdijati Gardjito ${ }^{2}$, Umar Santoso $^{2}$, Supriyadi $^{3}$ \\ ${ }^{1}$ Faculty of Agriculture, Tanjungpura University, Pontianak, West Kalimantan, Indonesia \\ ${ }^{2}$ Centre for Food and Nutrition Studies, Gadjah Mada University, Yogyakarta 55281, Indonesia \\ ${ }^{3}$ Department of Food and Agricultural Product Technology, Gadjah Mada University, Yogyakarta, Indonesia
}

\section{Email adress:}

sulvi_untan@yahoo.com(S. Purwayanti)

\section{To cite this article:}

Sulvi Purwayanti, Murdijati Gardjito, Umar Santoso, Supriyadi. Taste Compounds from Crude Extract of Bekkai lan (Albertisia papuana Becc.). Journal of Food and Nutrition Sciences. Vol. 1, No. 4, 2013, pp. 33-37. doi: 10.11648/j.jfns.20130104.11

\begin{abstract}
Bekkai lan leaves are commonly known as food flavoring in the culinary world of Dayak tribe, Borneo, Indonesia. No report has been made concerning the profile of the taste compounds in the extract of bekkai lan leaves. Thus, this study was aimed to investigate the profile of taste compounds in the leaves. The experiment was conducted on the crude extract of homemade leaves powder by using HPLC method. The results showed that the total content of taste compounds was $73.72 \mathrm{mg} / \mathrm{g}$ and there were 22 selected taste compounds from which the higher contribution came from some bitter compounds $(59.48 \mathrm{mg} / \mathrm{g})$ while the lower contribution came from solube sugars $(0.19 \mathrm{mg} / \mathrm{g})$ and salty compounds $(0.28$ $\mathrm{mg} / \mathrm{g}$ ). An analysis using the computation of DoT (Dose-over-Threshold) factors showed that gallic acid served as the dominant tastant with DoT factors of 279. This study finds that the higher concentration of taste compounds are not the higher the DoT factors. The taste compounds that potentially had an impact on the extract taste including tyrosine, Ca, P, Guanosine monophosphate (GMP), malic acid, alanine, valine, aspartic acid, methionine and Adenosine monophosphate (AMP). This finding is important to food scientists to understand the profile of taste compounds contributing to flavor in the crude extract leaves.
\end{abstract}

Keywords: Bekkai Lan, Taste Compounds, Dose Over Threshold

\section{Introduction}

Bekkai lan leaves are well-known as food flavoring in the Dayak tribe's foods. According to (1), flavoring can change, modify, enhance, mask, form or neutralize aroma. These flavoring can be either natural or synthetic flavoring. Although today synthetic flavoring is already available in the markets, however the natural flavoring still becomes the main option to obtain palatability. Some of the natural flavoring contains nutrition or phytochemicals that are essential to health of humans and more favorable than the synthetic one.

Taste is one of the flavor components which is important to consumer to evaluate the quality of foods. Traditionally, taste sensations are classified into five basic qualities: sour, sweet, salty, bitter, and umami. Although most of researchers reported that aroma compounds influenced more to the food flavor, the taste compounds have been identified as a precursor to aroma. Most of researchers report about the contribution of taste compounds from animal-derived food material, while that from plant-derived compounds is rarely reported. Some of the precursors were amino acids, sugars, nucleotides, organic acids and minerals. These compounds are well-known as taste active of food ingredients $(2 \& 3)$. Many studies of taste active have been reported: in oval squid (4), cheese (5\& 6), crab (7), mushrooms (8\& 9), fish (10), soy sauce (11), tomato juice (12), dried scallop (13), green tea (14). Although the perception of taste is so complicated due to the great number of involved taste and aroma compounds, the role/contribution of taste compounds of extract still needs to be investigated. Meanwhile, the taste active in bekkai lan leaves has never been reported. Therefore, the exploration of taste active is necessary.

\section{Materials and Methods}

\subsection{Plant Materials}

Bekkai lan leaf powder was obtained from the indigenous people of Dayak Kenyah tribe. The leaves were harvested in May, 2011 from the secondary forests surrounding the village of Long Lees (LU 0443 '37"; LS 00 87' 02.4") and the village 
of Long Pejeng (LU 0453 '58.5"; LS 00 85' 75, 2"), Busang Sub-district, East Kutai District, East Kalimantan Province, Indonesia. To obtain the leaf powder, fresh leaves were sliced, sun dried for 2 days, and milled or grounded into powder of $60 \mathrm{Mesh}$. The powder samples were then packaged in plastic containers, covered with aluminum foil paper, and stored at freezing temperature $\left(-20^{\circ} \mathrm{C}\right)$ until used.

\subsection{Preparation of Water Soluble Extraction}

Table 1. Profile of Taste Compounds in Crude extract of Bekkai lan, Treshold and The Value of DoT factors

\begin{tabular}{|c|c|c|c|c|c|}
\hline & \multicolumn{2}{|c|}{ Taste Compounds } & \multirow{2}{*}{$\begin{array}{l}\text { Concentration }(\mathbf{m m o l} / \mathbf{L}) \\
0.04\end{array}$} & \multirow{2}{*}{$\begin{array}{l}\text { Threshold }(\mathrm{mmol} / \mathrm{L}) * \\
12.50\end{array}$} & \multirow{2}{*}{$\begin{array}{l}\text { DoT } \\
0.003\end{array}$} \\
\hline 1 & & Sucrose & & & \\
\hline 2 & & Glucose & 0.03 & 48.00 & 0.001 \\
\hline 3 & I & Fructose & 0.96 & 5.00 & 0.19 \\
\hline 4 & Sweet & Alanine & 32.97 & 8.00 & 4.12 \\
\hline 5 & & serine & 18.22 & 30.00 & 0.61 \\
\hline 7 & \multirow{2}{*}{$\begin{array}{l}\text { II } \\
\text { Umami }\end{array}$} & AMP & 2.55 & 2.00 & 1.27 \\
\hline 8 & & GMP & 2.61 & 0.30 & 8.70 \\
\hline 9 & \multirow{3}{*}{$\begin{array}{l}\text { III } \\
\text { Acid }\end{array}$} & Malic acid & 16.37 & 3.70 & 4.43 \\
\hline 10 & & Oxalic acid & 2.75 & 5.60 & 0.49 \\
\hline 11 & & Glucuronic acid & 10.03 & - & - \\
\hline 12 & \multirow{5}{*}{$\begin{array}{l}\text { IV } \\
\text { Bitter }\end{array}$} & Tyrosine & 186.81 & 5.00 & 37.36 \\
\hline 13 & & Methionine & 10.66 & 5.00 & 2.13 \\
\hline 15 & & Isoleucine & 9.64 & 11.00 & 0.88 \\
\hline 16 & & Lysine & 30.84 & 34.20 & 0.90 \\
\hline 17 & & Gallic acid & 55.95 & 0.20 & 279.77 \\
\hline 18 & \multirow{5}{*}{$\begin{array}{l}\text { V } \\
\text { Salty }\end{array}$} & $\mathrm{Na}$ & 0.31 & 7.50 & 0.04 \\
\hline 19 & & $\mathrm{~K}$ & 3.53 & 15.00 & 0.24 \\
\hline 20 & & $\mathrm{P}$ & 3.14 & 0.16 & 19.46 \\
\hline 21 & & $\mathrm{Ca}$ & 0.09 & 3.12 & 29.11 \\
\hline 22 & & $\mathrm{Mg}$ & 1.30 & 4.00 & 0.32 \\
\hline
\end{tabular}

Note: - = no data or no references

* Taste threshold value according to $(7,9,14,22-24)$

\subsection{Chemical Analysis}

Chemical analysis were performed on water-soluble extracts such as free amino acid compounds (15) with a modification method as proposed by (16), soluble sugar compounds (17), sour compounds (18), 5'-nucleotides (19), phenolic acid compounds (20). The salt analysis ( $\mathrm{Na}, \mathrm{K}, \mathrm{Mg}$, $\mathrm{Ca}$ was performed using an atomic absorption spectrophotometer (AAS) while the phosphate was analyzed photometrically (21).

\subsection{DoT Analysis}

The DoT factors were calculated as the ratio between the concentration of each compound in samples and its corresponding taste threshold (14).

\subsection{Statistical Analysis}

The data results were tabulated and analyzed descriptively
The process of making extracts from powder leaves was as follows: $5 \mathrm{~g}$ of sample was homogenized in $150 \mathrm{ml}$ water $(1 / 30 ; \mathrm{g} / \mathrm{v})$. Vortex and mixed until dissolved leaves for approximately 5 minutes and boiled $\left(100 \mathrm{C}^{\circ}\right)$ for 3 minutes. The mixture was vacuum filtered and the residues were re-extracted with water in the previous stage. The collected filtrate referred to water soluble extract (WSE), freeze dried and stored at freezing temperatures $\left(-20^{\circ} \mathrm{C}\right)$ until used. 
ethanol (25\& 26) or methanol (27), the soluble carbohydrate is also able to be extracted from hot water as reported by (28). Reports by ( 29 \& 30) that organic acids can be extracted from the crude extract while the most efficient extraction is performed by alkaline medium (31).

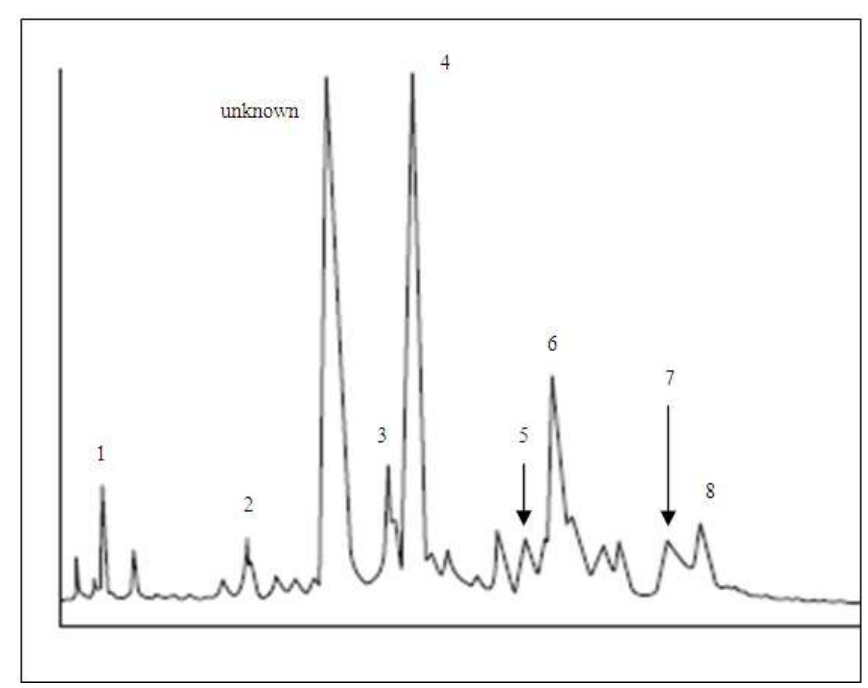

Fig 1. Chromatogram of the amino acid: (1) aspartic acid; $r t 2.255,(2)$ serine; $r$ 10.221,(3) alanine; $r$ 17.940,(4)tyrosine; $r$ 19.173,(5)methionine; rt 25.370, (6) valine; $r t 27.083$, (7)isoleucine ; rt29.743),(8) lysine; $r t 35.037$

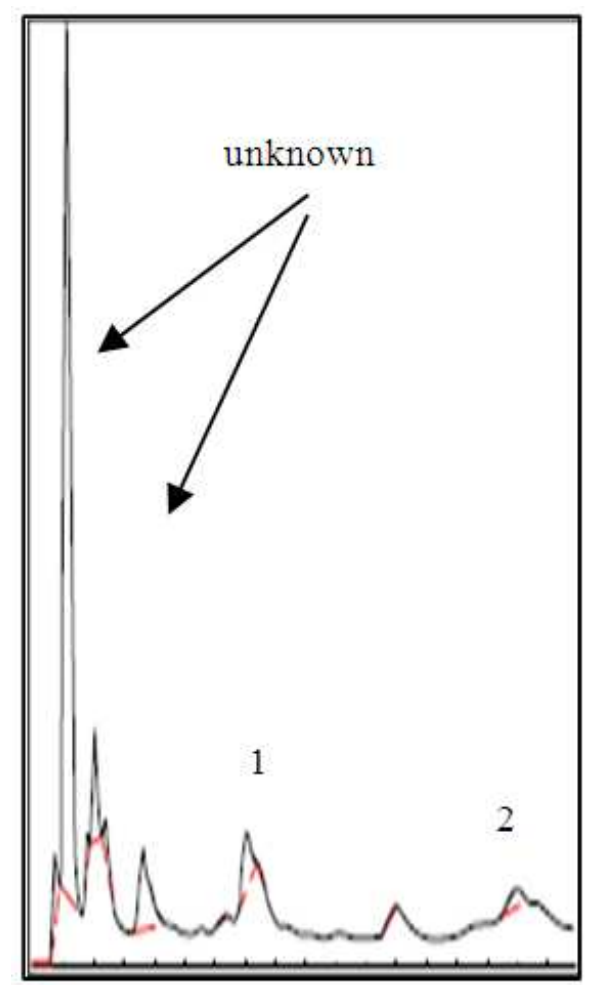

Fig 2. Chromatogram of umami 'nucleotides' (1) GMP (rt 9.094) and (2) AMP (rt 18.030)

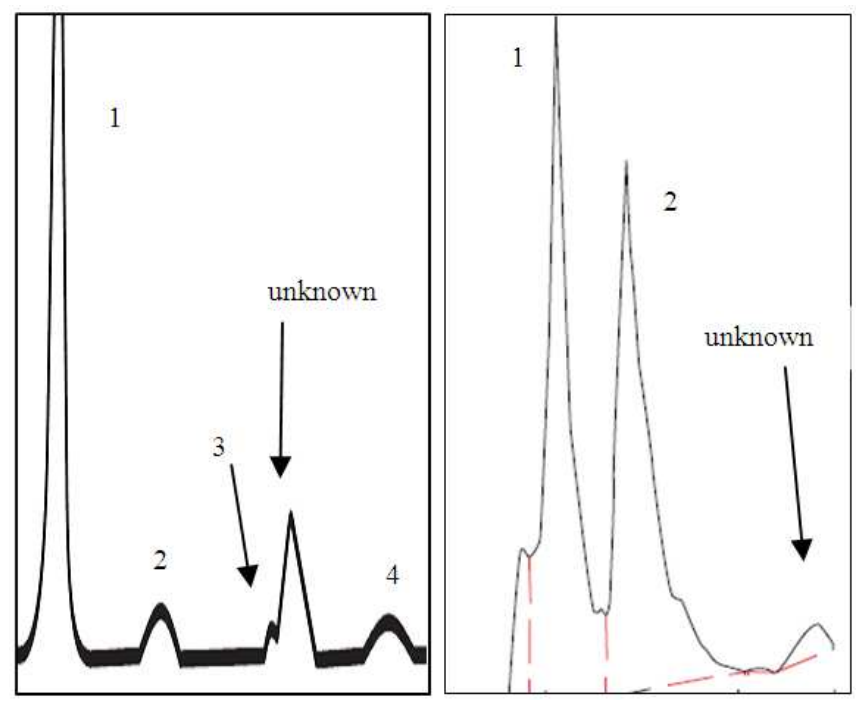

Fig 3(a). Chromatogram of the carbohydrate compounds: (1) glucuronic acid; rt 5.64, (2) sucrose; rt 7.602, (3) glucose; $r t$ 9.605 , (4) fructose; rt 11.908

Fig 3(b). Chromatogram of the organic acid compounds: (1) oxalic acid; rt 2.973 and (2) malic acid; $r t 3.43$

Interestingly, this study finds that gallic acid is the only of phenolic acids highly extracted from hot water (Fig.4). Our results consistent in reported by $(15,28-30,32,33)$, there for we sugested that the taste compounds can extracted directly from crude extract.

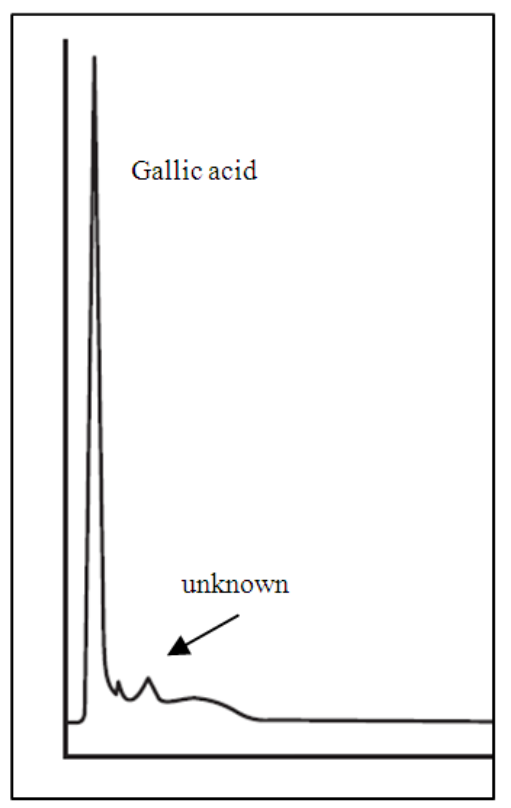

Fig 4. Chromatogram of gallic acid at rt 1.285

Table 2 showed that the total content of taste compounds in the extract was $73.72 \mathrm{mg} / \mathrm{g}$, from which the higher contribution comes from bitter compounds $(59.48 \mathrm{mg} / \mathrm{gr})$ especially from tyrosine which has the higher concentration $186.81 \mathrm{mmol} / 1$ (Table 1$) \approx 33.85 \mathrm{mg} / \mathrm{g}$. The compounds very low extracted are minerals $(0.28 \mathrm{mg} / \mathrm{g})$ and soluble sugars $0.19 \mathrm{mg} / \mathrm{g}$. 
Table 2. Total Content of Taste Compounds $(\mathrm{mg} / \mathrm{g})$

\begin{tabular}{ll}
\hline Taste Compounds & Content \\
\hline Soluble sugars & 0.19 \\
Sweet amino acid & 4.85 \\
Umami & 4.53 \\
Acid & 4.39 \\
Bitter & 59.48 \\
Salty & 0.28 \\
Total of taste compounds & 73.72 \\
\hline
\end{tabular}

Note: The value of content from converstion $\mathrm{mmol} / \mathrm{l}$ to $\mathrm{mg} / \mathrm{g}$ inTabel 1

\subsection{Calculation of DoT Factors}

The value of DoT factors $(9 \& 14)$ is the same as the value of taste activity (TAV) as claimed by ( $7 \& 34)$. Although they have different term, still they have the same meaning. The TAV value is obtained from the ratio between the concentration of sample and its threshold value, and generally measured in water or in a simple matrix (8). The compounds whose TAV values are $>1$ are considered as taste active compounds in food (8) while those having DoT factors of $>1$ can contribute to the taste $(4,18)$.

The evaluation of the contribution of each taste including 8 amino acids, 3 organic acids, 2 nucleotides, 5 inorganic salts, 3 soluble sugars and 1 phenolic acid is quantitatively conducted in the extract. Since the objective of this study is to elucidate the key contributors for each taste quality, one taste compound is grouped into five classes with different taste qualities (Table 1).

Tastant Group I, the compounds producing sweet taste containing sucrose, glucose, fructose and serine, shows a taste threshold concentration (DoT factors) of $<1$ while only alanine shows DoT factors of 4 . Meanwhile, Tastant group II are the compounds producing an umami-like taste sensation containing aspartic acid, AMP and GMP. All of the umami have DoT factors of 1-8. In contrast, the standard of umami taste (glutamic acid) can be not detected; it might be caused by the less concentration.

Tastant Group III are the compounds producing sour taste containing malic acid, oxalic acid, and glucuronic acid. Nevertheless, the taste threshold of glucuronic acid has not been reported yet so the analysis of DoT factors of glucuronic acid cannot be performed. In this group, only malic acid shows DoT factors of 4 . From the bitter tastant group (Table 1), it can be seen that gallic acid is the first bitter tastant with DoT factors of $>1$ and exceeds its own threshold concentration in extract by a value of 279. The second bitter tastant which also has high DoT factors is tyrosine. It is assumed that the tyrosine also significantly affects the taste of extract due to its Dot factors of 37.

The last tastant group (mineral), only cation $\mathrm{Ca}$ and $\mathrm{P}$ have DoT factors of $>1$ respectively. The DoT factors of $\mathrm{P}$ and $\mathrm{C}$ was 19 and 29, higher than other minerals which have DoT factors $<1(\mathrm{Na}, \mathrm{K}, \mathrm{Mg})$. This concentration implies that $\mathrm{Ca}$ and $\mathrm{P}$ were great potential to have an impact on the taste of extract. Since the taste compounds which have DoT factors of
1-10 may have less impact on the extract taste.

In regard with the data above, the sweet compounds from soluble sugar are not important in the responsible on taste of bekkai lan leaves.

\section{Conclusion}

The profile of taste compounds in the extract of bekkai lan leaves has been identified in this study. Gallic acid and tyrosine shows higher DoT factors. We concluded that 11 of taste compounds (gallic acid, tyrosine, Ca, P, GMP, malic acid, alanine, valine, aspartic acid, methionine and AMP has been responsible for taste of crude extract bekkai lan leaves based on DoT factors.

\section{References}

[1] W. Cahyadi, "Analisis \& Aspek Kesehatan Bahan Tambahan Pangan,” Bumi Aksara. Jakarta, hal. 102-113, 2008.

[2] H. Ottinger, and T. Hofmann, "Identification of the taste enhancer alaypyridaine in beef broth and evaluation of its sensory impact by taste reconstitution experiments," Journal of Agricultural Food Chemistry, 2003, 51, pp. 6791-6796

[3] M. S. Madruga, J. S. Elmore, M. J. Oruna-concha, D. Balagiannis, and D. S. Mottram "Determination of some water-soluble aroma precursors in goat meat and their enrolment on flavor profile of goat meat," Food Chemistry, 2010, 123, pp. 513-520

[4] Y. Kani, N. Yoshikawa, S. Okada, and H. Abe, "Taste-active components in the mantle muscle of the oval squid Sepioteuthis lessoniana and their effects on squid taste," Food Research International, 2008, 41, pp. 371-379

[5] L. T. Andersen, Y. Ardo, and W. L. P. Bredie, "Study of taste-active compounds in the water-soluble extract of mature Cheddar cheese," International Dairy Journal, 2010, 20, pp. 528-536

[6] E. Engel, C. Septier, N. Leconte, C. Salles, and J. Le Querre, determinantion of taste active compounds of a bitter camembert cheese by omission test," Journal of dairy Research, 2001, 68, pp. 675-688

[7] D. W. Chen, and M. Zhang, "Non-volatile taste active compounds in the meat of Chinese mitten crab (Eriorcheir sinensis)," Food Chemistry, 2007, 104, pp. 1200-1205

[8] I. H. Cho, H. K. Choi and Y. S. Kim, "Comparison of umami-taste active components in the pileus and stipe of Pine-mushrooms (Tricholoma matsutake Sing.) of different grades," Food Chemistry, 2010, 118, pp. 804-807

[9] N. Rotzoll, A. Dunkel, and T. Hofmann, "Quantitative studies, taste reconstitution, and omission experiment on the key taste compounds in morel mushrooms (Morechella deliciosa Fr.)," Journal of Agricultural Food Chemistry, 2006, 54, pp. 2705-2711.

[10] S. Kubota, K. Itoh, N. Nizeki, X. Song, K. Okimoto, M. Ando, M. Murata, and M. Sakaguchi, "Organic taste-active components in the Hot water-Extract of yellowtail Mucle," 2002, Food Science Technology Respectively, 2001, 8(1), pp. 45-49 
[11] H. N. Lioe, A. Apriyantono, K. Takara, K. Wada, H. Naoki, and M. Yasuda, "Low Molecular weight compounds responsible for savory taste of Indonesia soy sauce," Journal of Agricultural and Food Chemistry, 2004, 52, pp. 5950-5956.

[12] C. Salles, S. Nicklaus, and C. Septier, "Determination and gustatory properties of taste-active compounds in tomato juice," Food Chemistry, 2003, 81, pp. 395-402

[13] C. Starkenmann, I. C. Cayeux, E. Decorzant, E. X. Yang, Y. Niclass, and L. Nicolas, "Taste Contribution of (R)-Strombine to dired scallop," Journal of Agricultural Food Chemistry, 2009, 57, pp. 7936-7943

[14] S. Kaneko, K. Kumazawa, H. Masuda, A. Henze, and T. Hofmann, "Molecule and sensory studies on the umami taste of Japanese green tea," Journal of Agricultural Food Chemistry, 2006, 54 (7), pp. 2688-2694

[15] P. Sulvi, S. Umar, Supriyadi, and G. Murdijati, "Umami potential from crude extract of Bekkai lan (Albertisia papuana Becc.) leaves an indigenous plant in East Kalimantan-Indonesia," International Food Research Journal, 2010, 20(2), pp. 545-549

[16] H. Jork, W. Funk, W. Fwascher, and H. Wimmer, "Thin Layer Chromatography: reagents and detection methods," vol 1a (VCH Verlagsgeseeschaft mbH, Weinheim, Germany, 1990

[17] BioRad, "Guide to Aminex HPLC Coloumns for food and beverage biotechnology, and bio organic analysis," Bulletin 1928 US/EG REVA 94-0596 0994 SIG 071494, USA, 1994.

[18] J. Kowalski and B. Wittrig, "Simple, reliable HPLC Analyses of Organic Acid," Foods, Flavors \& Fragrances, 2007, 2, pp. $10-11$

[19] S. J. Huang, S. Y. Tsai, Y. L. Lee, and J. L. Mau, "Non volatile taste components of fruit bodies and mycelia of Cordyceps militaris, ”LWT, 2006, 39, pp. 577-583

[20] V. D. Truong, R. T. McFeeters, R. T. Thompson, L. L. Dean, and B. Shofran, "Phenolic Acid Content and Composition in Leaves and Roots of Common Commercial Sweet potato Ipomea batatas L.) Cultivars in the United States," Journal(of Food Science, 2007, 72 (6), pp. C343-C349

[21] T. A. Lene, A. Ylva, and L. P. B. Wender, "Study of taste-active compounds in the water-soluble extract of mature Cheddar cheese," International Dairy Journal, 2010, 20, pp. 528-536

[22] J. Kubickova, and W. Grosch, "Evaluation of Flavour Compounds of Camembert Cheese," International Dairy Journal, 1998, 8, pp.11-16

[23] T. Soldo, I. Blank, and T. Hofmann, “(+)-(S)-Alapyridaine-A General Taste Enhancer?," Chemical Senses, 2003, 28 (5), pp.371-379
[24] E.E. Lockhar, C. L. Tucker, and M. C. Merrit, "The effect of water impurities on the flavor of brewed coffee," Food Science, 1955, 20(6), pp. 598-605

[25] A. Moongngarm, N. Trachoo, and N. Sirigungwan, "Low molecular weight carbohydrate, prebiotic content, and prebiotic activity of selected food plants in Thailand," Advance Journal of Food Science and Technology, 2011, 3(4), pp. 269-274

[26] S. Chandraju, R. Mythily, and C. S. Kuar, "Extraction, isolation and identification of sugars fro Banana peels (Musa Sapienthum) by HPLC coupled LC/MS instrument and TLC analysis," Journal of Chemical and Pharmaceutical Reearch, 2011, 3(3), pp. 312-321

[27] T. Szczesna, "Study on the sugar composition of honeybee-collected pollen," Journal of Apicultural Science, 2007, 51(1), pp. 15-22

[28] N. Benkeblia, and N. Shiomi, "Chilling effect on soluble sugars, respiration rate, total phenolics, peroxidase activity and dormancy of onion bulbs," Scientia Agricola, (Piracicaba, Braz.), 2004, 61 (3), pp. 281-285

[29] D. B. Gomis, M. J. Gutierrez, M. Alvarez, and J. J. M. Alonso, "Application of HPLC to Characterization and Control of Individual Acids in Apple Extracts and Ciders," Chromatographia, 1998, 25(12), pp. 1054-1058

[30] A. H. Aktas, S. Sen, M. Yilmazer, and E. Cubuk, "Determination of carcboxylic acids in apple juice by RP-HPLC," Iran Journal Chemical \& Chemical Engineering, 2005, 24 (1), pp. 1-6

[31] F. Attia, F. Garcia, E. Besnard, M. F. Kasraaoui, and M. GarciaM, "Improvement of organic acids extraction and determination methods from leaves and berries of two grape cultivars cot and negrette," Invino Analytica Scientia, Montpellier, Juillet, France, 2005

[32] G. Taborda, A. Jose, Gomez-Ruiz, I. Martinez-Castro, L. Amigo, M. Ramos, and Molina, E, "Taste and flavor or artisan and industrial manchego cheese as influenced by the water-soluble extract compounds," European Food Research and Technology, 227, pp. 323-330

[33] Y. L. Dang, Z. Wang, and S. Y. Xu, "Methods for extracting the taste compounds from water soluble extract of Jinhua ham," European Food Research and Technology, 2008, 228, pp. $93-102$

[34] R. Warmke, H. Belitz, and W. Grosch, "Evaluation taste compounds of Swiss cheese (Emmentaler)," Z Lebensm Unters Forsch, 1996, 203, pp. 230-235 